\title{
Schematic Depiction of Conceptual Relationships among Domains of Job Performance and Employee Responsible Behaviors
}

Brenton M. Wiernik, Deniz S. Ones, Stephan Dilchert

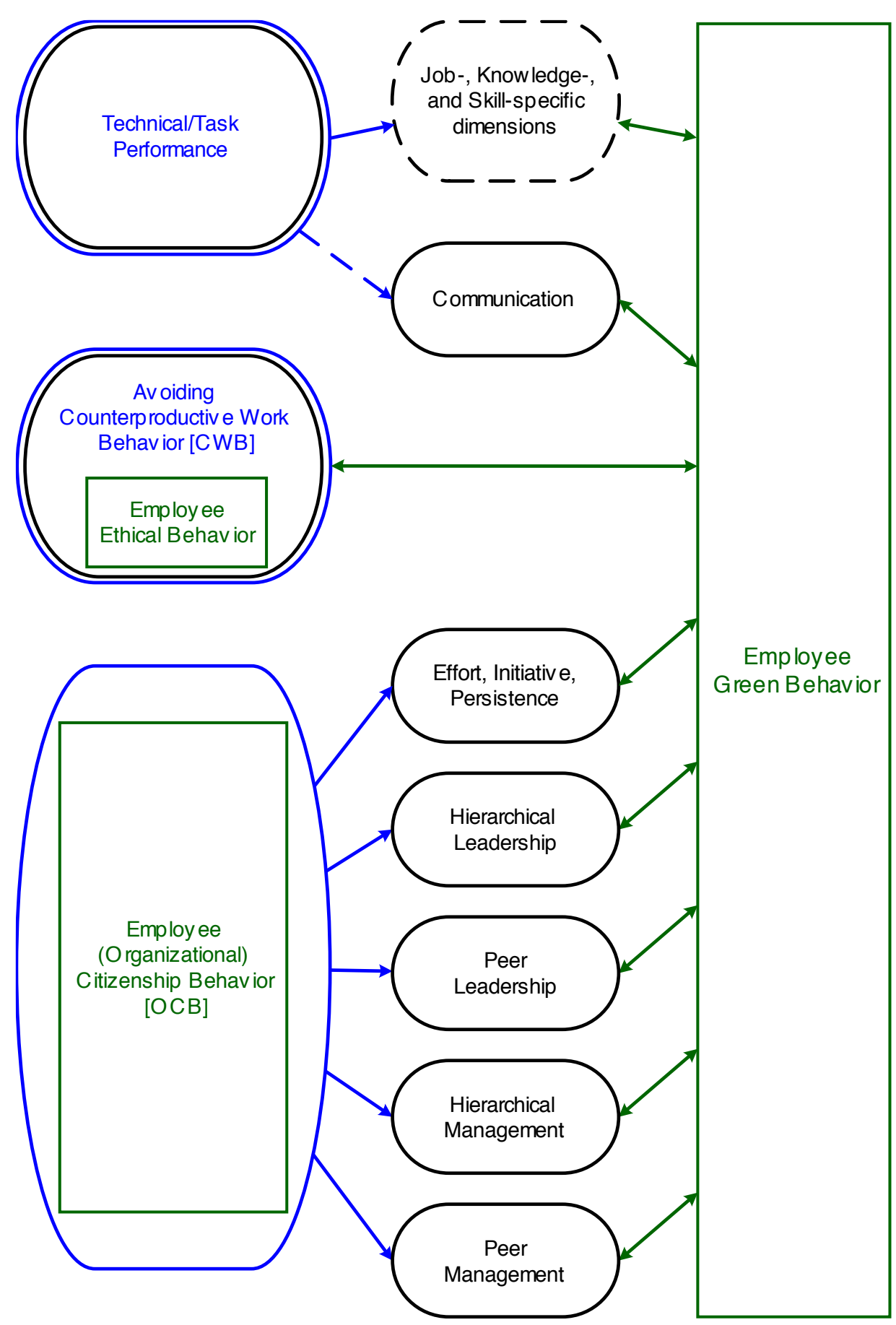

Note. Black ellipses are Campbell and Wiernik's (2015) eight job performance factors. Blue ellipses are the Big Three performance factors described by Viswesvaran and Ones (2000). Rectangles are employee responsible behavior domains. Employee (organizational) citizenship behavior is a higher-order factor above Campbell and Wiernik's leadership, management, and effort/initiative factors. Employee ethical behavior is sub-category within avoiding counterproductive work behavior. Employee green behavior can connect with any of Campbell and Wiernik's eight performance factors; it is a compound performance factor encompassing all employee behaviors that impact environmental sustainability. 


\section{References}

Campbell, J. P., \& Wiernik, B. M. (2015). The modeling and assessment of work performance. Annual Review of Organizational Psychology and Organizational Behavior, 2, 47-74. https://doi.org/10/bc4k

Viswesvaran, C., \& Ones, D. S. (2000). Perspectives on models of job performance. International Journal of Selection and Assessment, 8(4), 216-226. https://doi.org/10/ctcc82 